\title{
Finding the Optimal Regimen for Short-Term Daily Recombinant Human Erythropoietin Treatment for Blood-Saving Purpose in Patients undergoing Unilateral Primary Total Hip Arthroplasty: A Double- Blinded Randomized Placebo-Controlled Trial
}

\author{
Mingcheng Yuan \\ West China Hospital, Sichuan University \\ Qifeng Tao \\ Panzhihua Municipal Central Hospital Panzhihua \\ Duan Wang \\ West China Hospital, Sichuan University \\ Haoyang Wang \\ West China Hospital, Sichuan University \\ Zongke Zhou ( $\square$ zongkehx@126.com ) \\ West China Hospital, Sichuan University
}

\section{Research Article}

Keywords: total hip arthroplasty, recombinant human erythropoietin, blood-saving, optimal regimen

Posted Date: September 27th, 2021

DOl: https://doi.org/10.21203/rs.3.rs-761058/v1

License: (c) (i) This work is licensed under a Creative Commons Attribution 4.0 International License.

Read Full License

Version of Record: A version of this preprint was published at BMC Musculoskeletal Disorders on March 12th, 2022. See the published version at https://doi.org/10.1186/s12891-022-05184-1. 


\section{Abstract}

Purpose: To find the best short-term daily rhEPO-based treatment protocols for blood-saving purpose in THA.

Method: The patients were randomized to 1 of 3 interventions: Patients in group A received 10,000 IU $(150 \mathrm{IU} / \mathrm{kg}$ ) of subcutaneous rhEPO $(1 \mathrm{ml})$ daily from 5 days preoperatively to 3 days postoperatively ( 9 doses in total); Patients in group B received $1 \mathrm{ml}$ of subcutaneous normal saline daily from 5 days preoperatively to 4 days preoperatively and then $10,000 \mathrm{IU}(150 \mathrm{IU} / \mathrm{kg})$ of subcutaneous rhEPO daily till 3 days postoperatively ( 6 doses in total). Patients in group $C$ received $1 \mathrm{ml}$ of subcutaneous normal saline daily from 5 days preoperatively to one day preoperatively and then 10,000 IU (150IU/ kg) of subcutaneous rhEPO daily from the day of surgery to 3 days postoperatively (4 doses in total).

Results: 180 patients were included. On postoperative day one, patients in the group A showed significantly higher $\mathrm{Hb}$ level $(108.4 \pm 11.4 \mathrm{~g} / \mathrm{L})$ than group $B$ and $\mathrm{C}(107.8 \pm 8.4$ and $103.9 \pm 8.8 \mathrm{~g} / \mathrm{L}$, respectively) $(p<0.001)$, the $\mathrm{Hb}$ level in group $B$ was also markedly higher than in group $C(p=0.045)$. On postoperative day 3 , no significant difference was found between group $B$ and $C$ in $\mathrm{Hb}$ level $(98.7 \pm 10.5$ and $94.9 \pm 8.7 \mathrm{~g} / \mathrm{L}$, respectively) $(p=0.094)$, but the $\mathrm{Hb}$ level in group $A(103.6 \pm 11.0 \mathrm{~g} / \mathrm{L})$ was still markedly higher than in group $B$ and $C$. In terms of blood loss, no markedly difference was found in intraoperative blood loss among group A, B and C $(78.3 \pm 22.4,84.6 \pm 29.1$, and $80.3 \pm 23.9 \mathrm{ml}$, respectively) $(p=0.381)$, but on postoperative day one, the mean blood loss was significantly more in groups $B$ and $C(371.2 \pm 124.6$, and $522.4 \pm 189.4 \mathrm{ml}$, respectively) than in group $A(284.8 \pm 112.9 \mathrm{ml})(\mathrm{p}<0.001)$, and group $B$ had significantly less blood loss than group $C(p<0.001)$. With respect to the total blood loss, group $B$ and $C$ had markedly more total blood loss $(642.6 \pm 232.9$, and $881.6 \pm 314.9 \mathrm{ml}$, respectively) than group $A$ $(514.5 \pm 204.6 \mathrm{ml})$ and group $B$ had significantly less blood loss than group $C(p<0.001)$ (Table 2). Only 2 patients in each group received allogeneic blood transfusion and each patient received 2 units of red blood cells, so, the transfusion requirements among the three groups were comparable.

Conclusions: Daily small-dose of subcutaneous rhEPO administered from 5 days before THA could significantly decrease perioperative blood loss and improve postoperative $\mathrm{Hb}$ levels, without increasing risks of complications, when compared with the application of rhEPO from 3 days before THA or from the day of surgery. Therefore, we recommend the more practical and highly effective therapeutic regimen of small-dose of subcutaneous rhEPO daily from 5 days preoperatively to 3 days postoperatively for patients scheduled for THA.

\section{Background}

Total hip arthroplasty (THA) is an effective treatment which provides pain relief and function restoration to patients suffering from end-stage hip arthropathy. Over 500,000 THAs are performed each year in the UK and USA (1). Approximately 400,000 primary THAs were performed in China in 2015, a number that has been increasing by $25 \%-30 \%$ per year (2). However, most patients undergoing THA are elderly and 
combined with a high prevalence (24\%) of preoperative anemia, which is widely accepted as a predictive factor of postoperative allogeneic transfusion. Moreover, the procedure is also associated with substantial blood loss leading to a high prevalence (51\%) of postoperative anemia which may therefore cause the relatively high rate (45\%) of postoperative allogeneic blood transfusion (3). Allogeneic transfusion carries a substantial risk of transfusion-associated complications requiring additional treatment and increased length of stay (4). Many blood-saving strategies have been reported, of which recombinant human erythropoietin (rhEPO) has demonstrated effectiveness in reducing hemoglobin $(\mathrm{Hb})$ level drop and blood transfusion requirements according to numerous randomized controlled trials (5-9).

For now, there exists two main protocols of the perioperative use of rhEPO in patients who are scheduled for total joint arthroplasty (TJA). One is weekly application of large-dose rhEPO for 2-4 weeks before surgery, which is called the long-term regimen (9). The other one is daily application of small-dose rhEPO from $0-5$ days preoperatively to a few days (less than a week) postoperatively, which is called the shortterm regimen (5-8). However, the weekly protocol has some obvious drawbacks: The long-term of treatment requested the patients to come back to hospital weekly for injections, which would therefore cause inconvenience to the patients and it would also increase the preoperative waiting interval. When encountering patients with poor compliance, it would be even more difficult to implement the treatment. Besides, initial high peak levels from high once weekly doses may be wasted, as erythropoietin receptors on progenitor cells in bone marrow may become saturated; when these receptors are again free for binding, the level of serum erythropoietin will fall (10). Compared with the weekly protocol, the short-term daily protocol with small amounts of rhEPO could maintain a more constant low but more effective level of serum erythropoietin without causing inconvenience to the patient (10). Besides, previous studies also reported that repeated administration of rhEPO is more effective in stimulating the reticulocyte response than the weekly large-dose of the same total amount of rhEPO (11).

Cao et al [6] advocated that a daily dose $(150 \mathrm{IU} / \mathrm{kg})$ of rhEPO started from 3 days before arthroplasty is more effective than being applied from the day of surgery in increasing $\mathrm{Hb}$ level, reducing blood loss without additional complications, they also concluded that the application of rhEPO since the day of surgery cannot significantly reduce the blood loss or increase the $\mathrm{Hb}$ level after arthroplasty compared with no application of rhEPO. On the contrary, $\mathrm{Na}$ et al (8) applied $3000 \mathrm{IU}$ of rhEPO subcutaneously during the operation and the postoperative period, they found that compared with the control (placebo) group, application of rhEPO since the day of surgery could effectively attenuated anemia and decreased transfusion requirements in patients undergoing arthroplasty, which was coincident with the conclusion of Bernabeu-Wittel et al (5) with the similar rhEPO regimen. Furthermore, Kourtzis et al (7) advocated the rhEPO regimen that each patient undergoing arthroplasty received 10,000 IU (150 IU/kg) of rhEPO daily subcutaneously for 5 days preoperatively and 3 days postoperatively which is also the current protocol implemented in our center, they found a markedly reduction of $94 \%$ in the utilization of allogeneic blood in patients received the rhEPO protocol than the control (placebo) group. Although there exist various regimens, the optimal regimen of short-term daily administration of rhEPO for THA patients are yet to be established. 
In this study, a prospective double-blinded randomized placebo-controlled trial comparing three different short-term daily rhEPO-based treatment protocols for blood-saving purpose in THA was conducted. We hypothesized that the daily small-dose of rhEPO started from 5 days before THA which is the current protocol in our center is more effective in blood-saving than starting rhEPO treatment from 3 days preoperatively and the protocol of applying rhEPO from the day of surgery.

\section{Patients And Methods}

This double-blinded randomized placebo-controlled trial was registered in the Chinese Clinical Trial Registry (20/09/2019) and the registration number is ChiCTR1900026064. Approval was obtained from the Clinical Trials and Biomedical Ethics Committee of West China Hospital. The study was conducted at the Department of Joint Surgery of West China Hospital, Sichuan University, in accordance with the CONSORT (Consolidated Standards of Reporting Trials) Statement. Written informed consent was obtained from all participants prior to surgery.

\section{Patients}

We recruited consecutive adult patients (18 to 85 years of age) from September 2019 to May 2020 who were scheduled for primary unilateral total hip arthroplasty. Exclusion criteria included a diagnosis other than osteoarthritis or osteonecrosis of the femoral head, a known allergy to rhEPO or ferralia, an $\mathrm{Hb}$ level more than $130 \mathrm{~g} / \mathrm{L}$ or less than $90 \mathrm{~g} / \mathrm{L}$, use of spinal anesthesia, a history of a hematopoietic or hemorrhagic disorder, a history of deep venous thrombosis (DVT) or pulmonary embolism (PE), an ongoing anticoagulant treatment with anticoagulant therapy (warfarin or heparin) within 1 week prior to surgery, an ongoing treatment with ferralia and/or rhEPO within 3 months before admission, preoperative hepatic or renal dysfunction and serious cardiac and/or cerebrovascular comorbidities, and refusal of participation.

\section{Interventions and surgical procedures}

The patients were randomized to 1 of 3 interventions: Patients in group A received 10,000 IU (150IU/kg) of subcutaneous rhEPO $(1 \mathrm{ml})$ daily from 5 days preoperatively to 3 days postoperatively ( 9 doses in total); Patients in group B received $1 \mathrm{ml}$ of subcutaneous normal saline daily from 5 days preoperatively to 4 days preoperatively and then $10,000 \mathrm{IU}(150 \mathrm{IU} / \mathrm{kg})$ of subcutaneous rhEPO daily till 3 days postoperatively ( 6 doses in total). Patients in group $C$ received $1 \mathrm{ml}$ of subcutaneous normal saline daily from 5 days preoperatively to one day preoperatively and then $10,000 \mathrm{IU}(150 \mathrm{IU} / \mathrm{kg})$ of subcutaneous rhEPO daily from the day of surgery to 3 days postoperatively (4 doses in total). If the Hb level was over $150 \mathrm{~g} / \mathrm{L}$, rhEPO was not administered. All patients received a $100 \mathrm{mg}$ (dissolved into $100 \mathrm{ml}$ of normal saline) dose of intravenous ferric carboxymaltose, which has been widely accepted as an effective partner with rhEPO for the blood-saving purpose in patients undergoing arthroplasty (8). The placebo (normal saline) has the same appearance (colorless and clear liquid) as rhEPO. 
All the THAs were performed by the same surgical team using a posterolateral approach and a single brand of cementless acetabular and femoral components (DePuy Synthes) under general anesthesia. No autologous blood transfusion or postoperative drain were used(12).

\section{Thromboembolism Prophylaxis and Transfusion Protocol}

All the patients received thromboembolic prophylaxis according to a standardized protocol at our institution, which is a combination of physical prophylaxis and chemoprophylaxis (12). The patients received physical prophylaxis by means of an intermittent inflatable pump system on the day after surgery. As for the chemoprophylaxis, a half-dose (2000 IU in $0.2 \mathrm{~mL}$ ) of low-molecular-weight heparin was given to patients subcutaneously 6 hours postoperatively and a full dose ( $4000 \mathrm{IU}$ in $0.4 \mathrm{~mL}$ ) was repeated at 24-hour intervals subsequently until discharge. After discharge, all patients routinely received $10 \mathrm{mg}$ rivaroxaban for 10 days. During hospitalization, the patients were examined daily for any clinical symptoms of DVT. Ultrasound examinations were also performed routinely at preoperatively, discharge, and the 2-week follow-up. A chest contrast-enhanced spiral computed tomography was performed immediately for any clinical signs of $\mathrm{PE}(12)$.

A standardized blood-transfusion protocol of the National Ministry of Health was followed for all patients: Blood transfusion was indicated for any patients with a $\mathrm{Hb}$ level of $<70 \mathrm{~g} / \mathrm{L}$, or a $\mathrm{Hb}$ level between 70 and $100 \mathrm{~g} / \mathrm{L}$ but with symptomatic anemia (severe mental status changes, palpitations, and/or pallor)(12).

\section{Outcome measurements}

The primary outcomes included the $\mathrm{Hb}$ levels of the three groups at different time points, the rate and amount of allogeneic transfusion, and intraoperative and total blood loss. Secondary outcomes included the reticulocyte count, complications and patient satisfaction level. All the blood samples were obtained before each injection of rhEPO at 7 time points (on the preoperative day 5, 3, and 1, and on the postoperative day $1,3,14$, and 21 ), except the operation day, on which blood samples were obtained both at one hour preoperatively and immediately after surgery. Blood loss was calculated from the change in hematocrit using the formula of Nadler et al and Gross plus the volume transfused $(13,14)$. Besides, all the complications, including DVT, PE and other adverse effects related to rhEPO (nausea, fever, headache, myalgia, etc.) were also assessed during the first 3 weeks postoperatively. Moreover, patient satisfaction level was evaluated with a simple satisfaction questionnaire at the time of discharge (15).

\section{Randomization and Blinding}

A random allocation sequence was computer-generated and concealed in consecutively numbered, opaque, sealed envelopes by a research statistician not involved in the data analysis. One of 2 experienced surgeons enrolled the patients, and the other one recorded basic detail. The envelope was opened after the enrollment of patients, and the study medication and placebo were prepared by a dedicated nurse not involved with patient care or outcome measurement. Patients, surgeons, anesthesiologists, care providers, and data collectors were all blinded to the allocation sequence. 


\section{Statistical Analysis and Sample Size}

The sample size was determined in relation to the difference in the postoperative decrease in $\mathrm{Hb}$ level among the 3 study groups using G*Power Version 3.1.7 (Franz Faul; UniKiel, Germany) software. On the basis of our preliminary data of 60 patients who underwent unilateral primary total hip arthroplasty and were assessed for the same measure, the mean decrease in $\mathrm{Hb}$ level (and standard deviation) was $41.5 \pm$ $6.39 \mathrm{~g} / \mathrm{dL}$. A reduction of $10 \%(4 \mathrm{~g} / \mathrm{dL})$ in the decrease in $\mathrm{Hb}$ level in the experimental group (daily dose of 10,000 IU from 5 days preoperatively to 3 days postoperatively) compared with the control group (placebo only) was recorded as a clinically meaningful difference. On the basis of this information, 60 patients were required in each arm, with an alpha of $5 \%$, power of $85 \%$, and an anticipated $20 \%$ dropout rate.

Distributions of demographic data, baseline data, surgical characteristics, and primary and secondary outcomes were assessed using measures of central tendency (mean, standard deviation) for quantitative variables and with percentages for qualitative variables. Continuous variables were compared using oneway analysis of variance. When significant differences were detected, the 3 experimental groups were compared with each other using the Tukey's post hoc honest significant difference test. Categorical variables were compared using the chi-squared or Fisher's exact tests. All data analyses were performed using SPSS for Windows, Version 19.0 (SPSS Inc, Chicago, IL). Significance was set at $P<0.05$.

\section{Result}

From September 2019 to May 2020, 223 patients scheduled for primary unilateral THA were evaluated for eligibility, of which a total of 43 patients were excluded (32 did not meet the inclusion criteria and 10 declined to participate). Finally, the rest 180 patients were randomly assigned to 1 of the 3 groups (60 patients in each group) (Fig. 1). During the follow-up period of postoperative 3 weeks, no patient was lost or excluded for any reason. Patient demographic and preoperative characteristics in all the three groups were comparable (Table 1). 
Table 1

Baseline Demographic and Clinical Characteristics

\begin{tabular}{|c|c|c|c|c|}
\hline Variable & Group A $(n=60)$ & Group B $(n=60)$ & Group C $(n=60)$ & P Value \\
\hline \multicolumn{5}{|l|}{ Demographic characteristic } \\
\hline Age & $66.40 \pm 9.82$ & $63.21 \pm 10.82$ & $64.38 \pm 9.14$ & 0.2093 \\
\hline Female (no. [\%] of patients) & $39(65.0 \%)$ & $34(56.7 \%)$ & $36(60.0 \%)$ & 0.643 \\
\hline Height & $1.60 \pm 0.07$ & $1.62 \pm 0.06$ & $1.61 \pm 0.07$ & 0.2636 \\
\hline Weight & $64.12 \pm 9.84$ & $65.73 \pm 10.15$ & $66.31 \pm 9.91$ & 0.4611 \\
\hline BMI & $26.11 \pm 4.02$ & $25.81 \pm 3.87$ & $26.52 \pm 3.41$ & 0.5868 \\
\hline \multicolumn{4}{|l|}{ Operated side (no. of patients) } & 0.420 \\
\hline Left & 31 & 26 & 33 & \\
\hline Right & 29 & 34 & 27 & \\
\hline \multicolumn{4}{|l|}{ Diagnosis (no. of patients) } & 0.849 \\
\hline ONFH & 22 & 25 & 23 & \\
\hline $\mathrm{OA}$ & 38 & 35 & 37 & \\
\hline \multicolumn{4}{|l|}{ ASA class (no. of patients) } & 0.734 \\
\hline I & 11 & 13 & 12 & \\
\hline ॥ & 43 & 40 & 41 & \\
\hline III & 6 & 7 & 7 & \\
\hline \multicolumn{5}{|l|}{ Preoperative laboratory values } \\
\hline Hemoglobin (g/L) & $120.7 \pm 9.3$ & $119.9 \pm 10.4$ & $122.4 \pm 9.2$ & 0.3509 \\
\hline Reticulocyte (×10^12/L) & $0.0676 \pm 0.031$ & $0.0714 \pm 0.028$ & $0.0663 \pm 0.025$ & 0.5929 \\
\hline \multicolumn{5}{|c|}{$\begin{array}{l}\text { BMI, body mass index; ONFH, osteonecrosis of femoral head; OA, osteoarthritis; ASA, American } \\
\text { Society of Anesthesiologists }\end{array}$} \\
\hline
\end{tabular}

\section{Primary outcome}

On postoperative day one, patients in the group A showed significantly higher $\mathrm{Hb}$ level $(108.4 \pm 11.4 \mathrm{~g} / \mathrm{L})$ than group $B$ and $C(107.8 \pm 8.4$ and $103.9 \pm 8.8 \mathrm{~g} / \mathrm{L}$, respectively $)(p<0.001)$, the $\mathrm{Hb}$ level in group $B$ was also markedly higher than in group $C(p=0.045)$. However, on postoperative day 3 , no significant difference was found between group $B$ and $C$ in $\mathrm{Hb}$ level $(98.7 \pm 10.5$ and $94.9 \pm 8.7 \mathrm{~g} / \mathrm{L}$, respectively) $(p=$ 
0.094), even if the $\mathrm{Hb}$ level in group $\mathrm{A}(103.6 \pm 11.0 \mathrm{~g} / \mathrm{L})$ was still markedly higher than in group $\mathrm{B}$ and $\mathrm{C}$. No difference was found among the three groups at other time points. (Fig. 2).

In terms of blood loss, no markedly difference was found in intraoperative blood loss among group A, $B$ and $C(78.3 \pm 22.4,84.6 \pm 29.1$, and $80.3 \pm 23.9 \mathrm{ml}$, respectively $)(p=0.381)$, but on postoperative day one, the mean blood loss was significantly more in groups B and C $(371.2 \pm 124.6$, and $522.4 \pm 189.4 \mathrm{ml}$, respectively) than in group $A(284.8 \pm 112.9 \mathrm{ml})(p<0.001)$, and group $B$ had significantly less blood loss than group $C(p<0.001)$. With respect to the total blood loss, group $B$ and $C$ had markedly more total blood loss $(642.6 \pm 232.9$, and $881.6 \pm 314.9 \mathrm{ml}$, respectively) than group A $(514.5 \pm 204.6 \mathrm{ml})$ and group $B$ had significantly less blood loss than group $C(p<0.001)$ (Table 2$)$. Only 2 patients in each group received allogeneic blood transfusion and each patient received 2 units of red blood cells, so, the transfusion requirements among the three groups were comparable.

Table 2

Blood loss during the postoperative period

\begin{tabular}{|c|c|c|c|c|c|c|c|}
\hline \multirow[t]{2}{*}{ Variable } & \multirow[t]{2}{*}{$\begin{array}{l}\text { Group A } \\
(n=60)\end{array}$} & \multirow[t]{2}{*}{$\begin{array}{l}\text { Group B } \\
(n=60)\end{array}$} & \multirow[t]{2}{*}{$\begin{array}{l}\text { Group C } \\
(n=60)\end{array}$} & \multicolumn{4}{|c|}{$\begin{array}{l}\text { Pairwise Comparison ( } \mathrm{P} \\
\text { value) }\end{array}$} \\
\hline & & & & $\begin{array}{l}\text { Group } \\
\text { A vs B }\end{array}$ & $\begin{array}{l}\text { Group } \\
\text { A vs C }\end{array}$ & $\begin{array}{l}\text { Group } \\
\text { B vs C }\end{array}$ & $\begin{array}{l}\mathrm{P} \\
\text { Value }\end{array}$ \\
\hline $\begin{array}{l}\text { Intraoperative blood } \\
\text { loss }\end{array}$ & $\begin{array}{l}78.3 \pm \\
22.4\end{array}$ & $\begin{array}{l}84.6 \pm \\
29.1\end{array}$ & $\begin{array}{l}80.3 \pm \\
23.9\end{array}$ & 0.3621 & 0.9019 & 0.6215 & 0.3805 \\
\hline $\begin{array}{l}\text { Blood loss till } \\
\text { postoperative day } 1\end{array}$ & $\begin{array}{l}284.8 \pm \\
112.9\end{array}$ & $\begin{array}{l}371.2 \pm \\
124.6\end{array}$ & $\begin{array}{l}522.4 \pm \\
189.4\end{array}$ & $<0.01^{*}$ & $\begin{array}{l}< \\
0.001^{*}\end{array}$ & $\begin{array}{l}< \\
0.001^{*}\end{array}$ & $<.001^{*}$ \\
\hline Total blood loss & $\begin{array}{l}514.5 \pm \\
204.6\end{array}$ & $\begin{array}{l}642.6 \pm \\
232.9\end{array}$ & $\begin{array}{l}881.6 \pm \\
314.9\end{array}$ & $0.0179^{*}$ & $\begin{array}{l}< \\
0.001^{*}\end{array}$ & $\begin{array}{l}< \\
0.001^{*}\end{array}$ & $\begin{array}{l}< \\
0.001^{*}\end{array}$ \\
\hline
\end{tabular}

\section{Secondary outcome}

The reticulocyte count increased quickly after application of rhEPO. From 3 days preoperatively to 3 days postoperatively, reticulocyte counts in group $A$ were always higher than in group $B$ and $C(p<0.01)$. Besides, from the day before surgery to the day after surgery, reticulocyte counts in group B were always higher than in group $C(p<0.001)$ (Fig. 3). In terms of complications, no case of DVT occurred in any group, only a few cases of asymptomatic intermuscular vein thrombosis (IMVT) were observed in group $A(3,5.0 \%), B(3,5.0 \%)$ and $C(2,3.3 \%)$ without markedly difference among groups $(P=0.877)$. The all three regimens of rhEPO in this study were generally well tolerated, with few adverse events: nausea in 9 , pyrexia in 7 , headache in 4 , muscle pain in 4 patients but without markedly difference among all the three groups $(P>0.05)$ (Table 3). No case of death or readmission within postoperative 21 days occurred. Moreover, most patients were satisfied with the treatment they received. (Table 3). 
Table 3

Complications

\begin{tabular}{|lllll|}
\hline Variable & Group A $(n=60)$ & Group B $(n=60)$ & Group $(n=60)$ & P Value \\
\hline Complications & & & & \\
\hline DVT & 0 & 0 & 0 & NA \\
\hline IMVT & 3 & 3 & 2 & 0.877 \\
\hline Nausea & 3 & 2 & 2 & 0.704 \\
\hline Pyrexia & 3 & 2 & 1 & 0.862 \\
\hline Headache & 1 & 1 & 0.774 \\
\hline Muscle pain & 2 & 1 & 0.774 \\
\hline NA, not applicable; DVT, deep vein thrombosis; IMVT, intermuscular vein thrombosis & \\
\hline $\begin{array}{l}\text { The } p \text { value represents the result of the chi-squared test or Fisher's exact tests for categorical } \\
\text { variables among the 3 groups. }\end{array}$
\end{tabular}

\section{Discussion}

There is general agreement of the effective function of rhEPO in reducing transfusion requirements and accelerating the recovery of $\mathrm{Hb}$ level after THA (5-10). Despite the common application of rhEPO in total joint arthroplasty during the last decade, with benefits including attenuated $\mathrm{Hb}$ drop, decreased blood loss, and reduced transfusion requirement, no final consensus has been reached with respect to the optimal regimen, which is yet to be investigated.

Prior studies mostly focused on the application of rhEPO in TJA patients started from 2-4 weeks before surgery and each dose were large $(300-600 \mathrm{IU} / \mathrm{kg})$, and the protocol was generally accepted as the standard regimen $(9,16,17)$. However, the long-term of preoperative treatment requested the patients to come back to hospital weekly for injections, which would not only cause inconvenience to the patients but also increase the preoperative waiting interval. Contrary to the studies supporting the long-term and high-dose protocol, some investigators reported that more frequent perioperative application of smalldose rhEPO could be more efficacious. Cody et al (10) suggested that weekly high dose of rhEPO may be wasted for the limited erythropoietin receptors on progenitor cells in marrow which is easy to be saturated. When the receptors are saturated, no amount of rhEPO is effective until the receptors are again free for binding, but by then, the level of serum rhEPO would drop. So, frequent application of small-dose rhEPO could maintain a more constant low but more effective level of serum rhEPO. Similarly, Cheung et al (11) found that repeated application of rhEPO is more effective in stimulating the reticulocyte response than the single dose even if the total amount of rhEPO given to patients are the same. However, even if being applied in frequent small-dose, the rhEPO still has many regimens without a consensus. 
In this study, we summarized and compared the main three types of perioperative rhEPO regimens, and found: $\mathrm{Hb}$ levels in the three groups didn't show difference until the postoperative day one, when the $\mathrm{Hb}$ level in group A was significantly higher than in group B and C, in the meantime, $\mathrm{Hb}$ level in group B was also markedly higher than in group $\mathrm{C}$. In terms of transfusion requirement, no difference in either transfusion rates or amounts was found among all the three regimens even if the intraoperative and total blood loss in group $A$ was markedly less than those in group $B$ and $C$, but no significant difference was found between group $B$ and $C$. Few treatment-related adverse events occurred perioperatively, indicating the three regimens of rhEPO in this study were generally well tolerated, and no markedly difference in complication rates were observed among the three groups. So, we finally recommended the regimen of rhEPO started from 5 days preoperatively.

\section{Primary Outcomes}

\section{$\mathrm{Hb}$ levels}

It was reported that rhEPO could exert its effect of attenuating postoperative $\mathrm{Hb}$ drop soon after administration (8), and the $\mathrm{Hb}$ peaked on approximately 8-10 days subsequently (18). In this study, on postoperative day 1 , patients in group $A$ showed significantly higher $\mathrm{Hb}$ level than those in group $\mathrm{B}$ and $\mathrm{C}$, the $\mathrm{Hb}$ level in group $\mathrm{B}$ was also markedly higher than group $\mathrm{C}$, which indicated that the application of rhEPO started from 5 days preoperatively was better than 3 days and the day of surgery. On postoperative day 3 , when the $\mathrm{Hb}$ was the lowest during the postoperative period of THA and the transfusion also happened most likely in this period (19), patients in group A showed significantly higher $\mathrm{Hb}$ level than those in group $B$ and $C$, which also indicated the $\mathrm{Hb}$ drop of group $A$ was the least. The application of rhEPO in group A started 5 days before surgery which means that it has been 8 days till 3 days postoperatively when the erythropoiesis estimated by the rhEPO reached the peak, which is coincident with the prior studies. However, it was reported by Goodnough et al (20) that for patients subjected to a relatively large amount of blood loss, the endogenous erythropoietin response would be very substantial. Besides, in one clinical trial conducted by Goodnough et al (21), a linear-logarithmic relationship was demonstrated between change in $\mathrm{Hb}$ level and endogenous erythropoietin response, which meant that the more $\mathrm{Hb}$ drop, the stronger the endogenous erythropoietin response was, even if the effect is small. In this study, comparing postoperative day 1 and 3 , the $\mathrm{Hb}$ level between group $\mathrm{B}$ and $\mathrm{C}$ became comparable. It was the sharp drop of $\mathrm{Hb}$ in group $\mathrm{C}$ that led to a sharp increase of the endogenous erythropoietin response, which could therefore stimulate erythropoiesis quickly, while the drop of $\mathrm{Hb}$ level in group $\mathrm{B}$ was not so large that the exogenous rhEPO in group B still needed more time to stimulate erythropoiesis and promote the $\mathrm{Hb}$ level after surgery.

\section{Blood loss and transfusion}

It was reported that no matter under which kind of rhEPO regimen, the intraoperative blood loss would not be decreased: Kourtzis et al (7) applied rhEPO from preoperative 5 days and recorded the comparable intraoperative blood loss between study and control group. Similarly, Cao et al (6) recorded the 
intraoperative blood loss between two rhEPO regimens, one started from 3 days preoperatively and the other one from the day of surgery, and they found comparable intraoperative blood loss between the two groups. The trials above all indicated that the intraoperative blood loss is a parameter that has nothing to do with the application of rhEPO, which was also coincident with our study. In terms of total blood loss, we calculated the blood loss with the hematocrit (HCT) tested preoperatively and 3 days postoperatively (19). The trend of HCT was consistent with the $\mathrm{Hb}$ level, and the trend of Hb levels in the three groups were presented above, so, it was not surprise to find that total blood loss was significantly less in group $A$ than those in group $B$ and $C$, which suggested that the application of rhEPO 5 days before surgery could achieve the least total blood loss.

With respect to transfusion requirements, prior studies all reported that application of rhEPO, no matter under which regimen, would decrease the requirement of allogeneic transfusion $(5-10,16,17)$. However, in this study, only 2 patients in each group received allogeneic transfusion of 2 units of red blood cells. The very low transfusion requirements might due to the relatively little blood loss of patients in our center. The perioperative use of tranexamic acid (22), the intraoperative controlled hypotension as well as the application of rhEPO combined with ferralia all accounted for the little blood loss and the low transfusion rate.

\section{Secondary Outcomes}

\section{Reticulocyte count}

Because reticulocytes are normally released from the marrow 18 to 36 hours before their final maturation into erythrocytes, they provide a real-time assessment of the functional state of erythropoiesis (20). AitOudhia et al (18) discovered that blood reticulocyte count peaked on $72 \mathrm{hr}$ to day 5 after application of rhEPO. In this study, on the day before surgery, the reticulocyte count in group A and B were markedly larger than in group $\mathrm{C}$, which was consistent with the prior studies. In group $\mathrm{C}$, however, the application of rhEPO started from the day of surgery which was relatively late. So, we found that on postoperative day one the reticulocyte count in group $\mathrm{C}$ didn't increase as much as those in group $\mathrm{A}$ and $\mathrm{B}$. However, on postoperative day 3 the reticulocyte count in group $C$ caught up with the other two groups and finally on postoperative day 14 and 21 , no markedly difference was observed in reticulocyte count among the three groups, indicating that the marrow hematopoietic phase mobilized by perioperative application of rhEPO was over.

\section{Complications}

In theory, rhEPO could cause increased platelet count, enhanced blood viscosity, leading to hypercoagulability, thus increasing the risk of thrombosis $(23,24)$. Some investigators reported that patients after THA and TKA are naturally at high risk for developing DVT and the application of rhEPO might increase such risk, which limited the application of rhEPO to some extent $(23,24)$. However, in this study, no case of DVT were found in all the three groups. Only a few cases of asymptomatic IMVT were observed without markedly difference among groups. It was reported that no significant correlation was 
found between the incidence of postoperative PE and IMVT, and no special treatment to postoperative IMVT was needed (25). Besides, the three regimens of erythropoietin in this study were generally well tolerated, with few treatment-related adverse events such as nausea, pyrexia and headache and no difference were found in rates of different adverse events among three groups. Most patients were satisfied with the treatment they received during the whole hospitalization and follow-up phases.

\section{Limitation and advantage}

Although this study was carefully designed, several limitations still exist. First, the sample size was calculated according to the change in $\mathrm{Hb}$ level, which would be therefore not sufficient to identify a significant difference in other parameters like the transfusion rates and different complication rates. Second, we did not record the platelet count or the indexes related to coagulation such as D-dimer or Fibrin/Fibrinogen Degradation Products (FDP), so it might be inaccurate to judge that the three different regimens of rhEPO had no difference in the influence on patients' risk of DVT by simply recorded the rates of DVT or IMVT. The comparable rates of DVT among the three groups might also partly due to the anticoagulant therapy implemented in this study which has been proven to be efficacious and safe in our previous study (12). Finally, it was reported by prior studies that the application of rhEPO perioperatively could significantly increase the medical costs (26). However, in this study, we did not collect data with respect to the costs or conduct the cost-effective analysis.

\section{Conclusions}

Daily small-dose of subcutaneous rhEPO administered from 5 days before THA could significantly decrease perioperative blood loss and improve postoperative $\mathrm{Hb}$ levels, without increasing risks of complications, when compared with the application of rhEPO from 3 days before THA or from the day of surgery. Therefore, we recommend the more practical and highly effective therapeutic regimen of smalldose of subcutaneous rhEPO daily from 5 days preoperatively to 3 days postoperatively for patients scheduled for THA.

\section{Abbreviations}

rhEPO: Recombinant Human Erythropoietin; THA: total hip arthroplasty; BMI: body mass index; ONFH; osteonecrosis of femoral head; OA: osteoarthritis; ASA: American Society of Anesthesiologists; $\mathrm{Hb}$ : hemoglobin; Ret: reticulocyte; TJA: total joint arthroplasty; DVT: deep venous thrombosis; PE: pulmonary embolism; IMVT: intermuscular vein thrombosis

\section{Declarations}

\section{Ethics approval and consent to participate}

This double-blinded randomized placebo-controlled trial was registered in the Chinese Clinical Trial Registry. Approval was obtained from the Clinical Trials and Biomedical Ethics Committee of West China 
Hospital. The study was conducted at the Department of Joint Surgery of West China Hospital, Sichuan University, in accordance with the CONSORT (Consolidated Standards of Reporting Trials) Statement. Informed consent was obtained from all participants or, if participants are under 16 , from a parent and/or legal guardian.

\section{Consent for publication}

Not Applicable

\section{Availability of data and material}

Data used and analyzed in this study are available from the corresponding author on reasonable request.

\section{Competing interests}

The authors declare that they have no competing interests.

\section{Funding}

This work was supported by 1.3.5 project for disciplines of excellence, West China Hospital, Sichuan University (ZYJC18039) and Regional Innovation \& Cooperation program of Science \& Technology Department of Sichuan Province (No. 2021YFQ0028).

\section{Authors' contributions}

This study was conducted under the guidance of ZK-Z. The article was written by MC-Y and QF-T. The clinical assessment was done by D-W. The statistical analysis was performed by HY-W.

\section{Acknowledgements}

None

\section{References}

1. Pivec R, Johnson AJ, Mears SC, Mont MA. Hip arthroplasty. Lancet. 2012;380(9855):1768-77.

2. Ke-Rong D. Twenty-year accelerated development of artificial joints in China. Chin J Joint Surg. 2015:691-4. 
3. Spahn DR. Anemia and patient blood management in hip and knee surgery: a systematic review of the literature. Anesthesiology. 2010;113(2):482-95.

4. Bong MR, Patel V, Chang E, Issack PS, Hebert R, Di Cesare PE. Risks associated with blood transfusion after total knee arthroplasty. J Arthroplasty. 2004;19(3):281-7.

5. Bernabeu-Wittel M, Romero M, Ollero-Baturone M, Aparicio R, Murcia-Zaragoza J, Rincon-Gomez M, et al. Ferric carboxymaltose with or without erythropoietin in anemic patients with hip fracture: a randomized clinical trial. Transfusion. 2016;56(9):2199-211.

6. Cao SL, Ren Y, Li Z, Lin J, Weng XS, Feng B. Clinical effectiveness of 3 days preoperative treatment with recombinant human erythropoietin in total knee arthroplasty surgery: a clinical trial. QJM. 2020;113(4):245-52.

7. Kourtzis N, Pafilas D, Kasimatis G. Blood saving protocol in elective total knee arthroplasty. Am J Surg. 2004;187(2):261-7.

8. Na HS, Shin SY, Hwang JY, Jeon YT, Kim CS, Do SH. Effects of intravenous iron combined with lowdose recombinant human erythropoietin on transfusion requirements in iron-deficient patients undergoing bilateral total knee replacement arthroplasty. Transfusion. 2011;51(1):118-24.

9. So-Osman C, Nelissen RG, Koopman-van Gemert AW, Kluyver E, Pöll RG, Onstenk R, et al. Patient blood management in elective total hip- and knee-replacement surgery (Part 1): a randomized controlled trial on erythropoietin and blood salvage as transfusion alternatives using a restrictive transfusion policy in erythropoietin-eligible patients. Anesthesiology. 2014;120(4):839-51.

10. Cody J, Daly C, Campbell M, Donaldson C, Khan I, Vale L, et al. Frequency of administration of recombinant human erythropoietin for anaemia of end-stage renal disease in dialysis patients. Cochrane Database Syst Rev. 2005(3):CD003895.

11. Cheung WK, Goon BL, Guilfoyle MC, Wacholtz MC. Pharmacokinetics and pharmacodynamics of recombinant human erythropoietin after single and multiple subcutaneous doses to healthy subjects. Clin Pharmacol Ther. 1998;64(4):412-23.

12. Ding ZC, Xu B, Liang ZM, Wang HY, Luo ZY, Zhou ZK. Limited Influence of Comorbidities on Length of Stay after Total Hip Arthroplasty: Experience of Enhanced Recovery after Surgery. Orthop Surg. 2020;12(1):153-61.

13. Gross JB. Estimating allowable blood loss: corrected for dilution. Anesthesiology. 1983;58(3):27780.

14. Nadler SB, Hidalgo JH, Bloch T. Prediction of blood volume in normal human adults. Surgery. 1962;51(2):224-32.

15. Huang Z, Ma J, Shen B, Pei F. Combination of intravenous and topical application of tranexamic acid in primary total knee arthroplasty: a prospective randomized controlled trial. J Arthroplasty. 2014;29(12):2342-6.

16. Keating EM, Callaghan JJ, Ranawat AS, Bhirangi K, Ranawat CS. A randomized, parallel-group, openlabel trial of recombinant human erythropoietin vs preoperative autologous donation in primary total 
joint arthroplasty: effect on postoperative vigor and handgrip strength. J Arthroplasty. 2007;22(3):325-33.

17. Laffosse JM, Minville V, Chiron P, Colombani A, Gris C, Pourrut JC, et al. Preoperative use of epoietin beta in total hip replacement: a prospective study. Arch Orthop Trauma Surg. 2010;130(1):41-5.

18. Ait-Oudhia S, Scherrmann JM, Krzyzanski W. Time-dependent clearance and hematological pharmacodynamics upon erythropoietin multiple dosing in rats. Biopharm Drug Dispos. 2010;31(56):298-315.

19. Ma J, Huang Z, Shen B, Pei F. Blood management of staged bilateral total knee arthroplasty in a single hospitalization period. J Orthop Surg Res. 2014;9(116).

20. Goodnough LT, Skikne B, Brugnara C. Erythropoietin, iron, and erythropoiesis. Blood. 2000;96(3):82333.

21. Goodnough L, Price T, Parvin C, Friedman K, Vogler W, Khan N, et al. Erythropoietin response to anaemia is not altered by surgery or recombinant human erythropoietin therapy. British journal of haematology. 1994;87(4):695-9.

22. Luo ZY, Wang HY, Wang D, Zhou K, Pei FX, Zhou ZK. Oral vs Intravenous vs Topical Tranexamic Acid in Primary Hip Arthroplasty: A Prospective, Randomized, Double-Blind, Controlled Study. J Arthroplasty. 2018;33(3):786-93.

23. Clyne N, Berglund B, Egberg N. Treatment with recombinant human erythropoietin induces a moderate rise in hematocrit and thrombin antithrombin in healthy subjects. Thromb Res. 1995;79(1):125-9.

24. Lippi G, Franchini M, Favaloro EJ. Thrombotic complications of erythropoiesis-stimulating agents. Semin Thromb Hemost. 2010;36(5):537-49.

25. Guias B, Simoni G, Oger E, Lemire A, Leroyer C, Mottier D, et al. [Calf muscle venous thrombosis and pulmonary embolism]. J Mal Vasc. 1999;24(2):132-4.

26. Bedair H, Yang J, Dwyer MK, McCarthy JC. Preoperative erythropoietin alpha reduces postoperative transfusions in THA and TKA but may not be cost-effective. Clin Orthop Relat Res. 2015;473(2):5906.

\section{Figures}




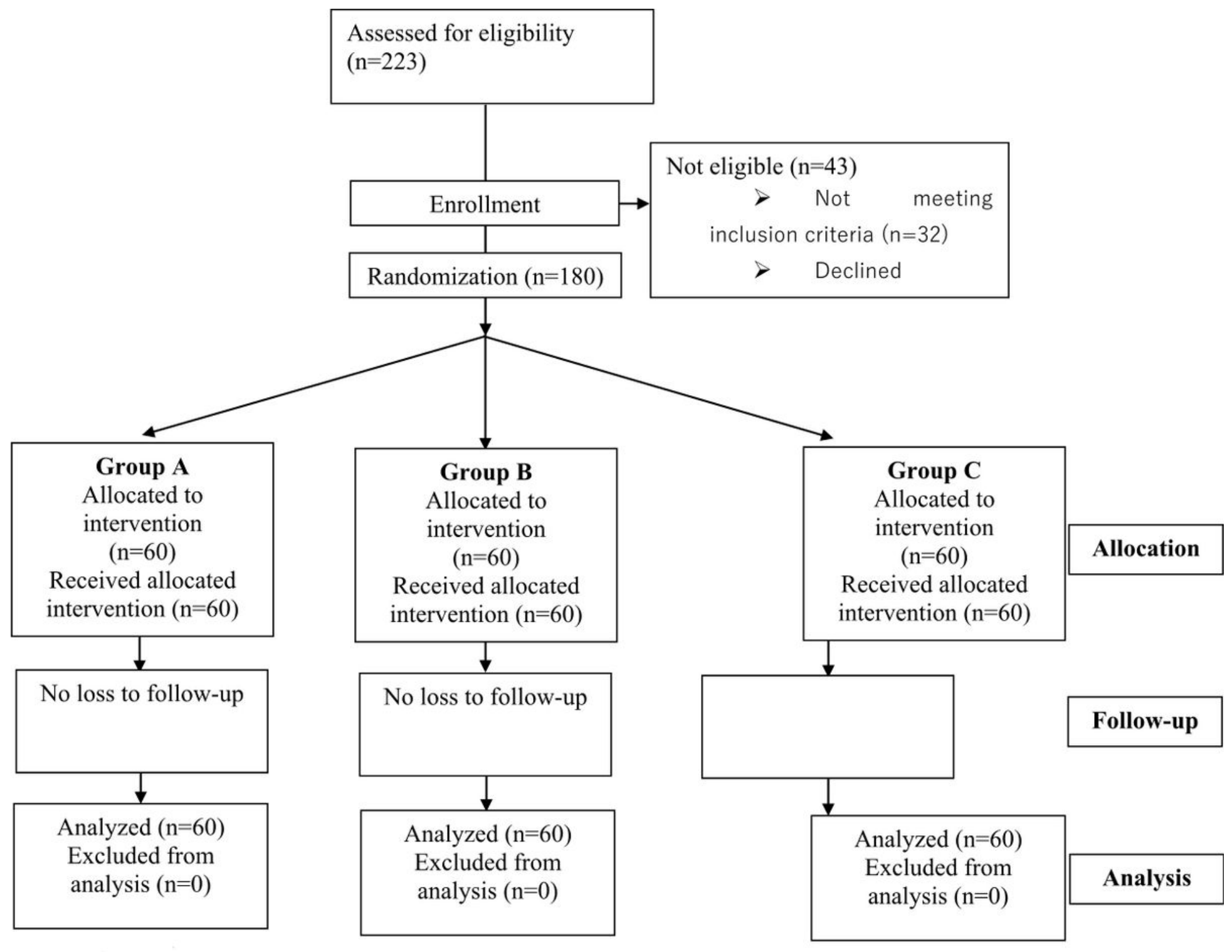

Figure 1

Patients flow chart 


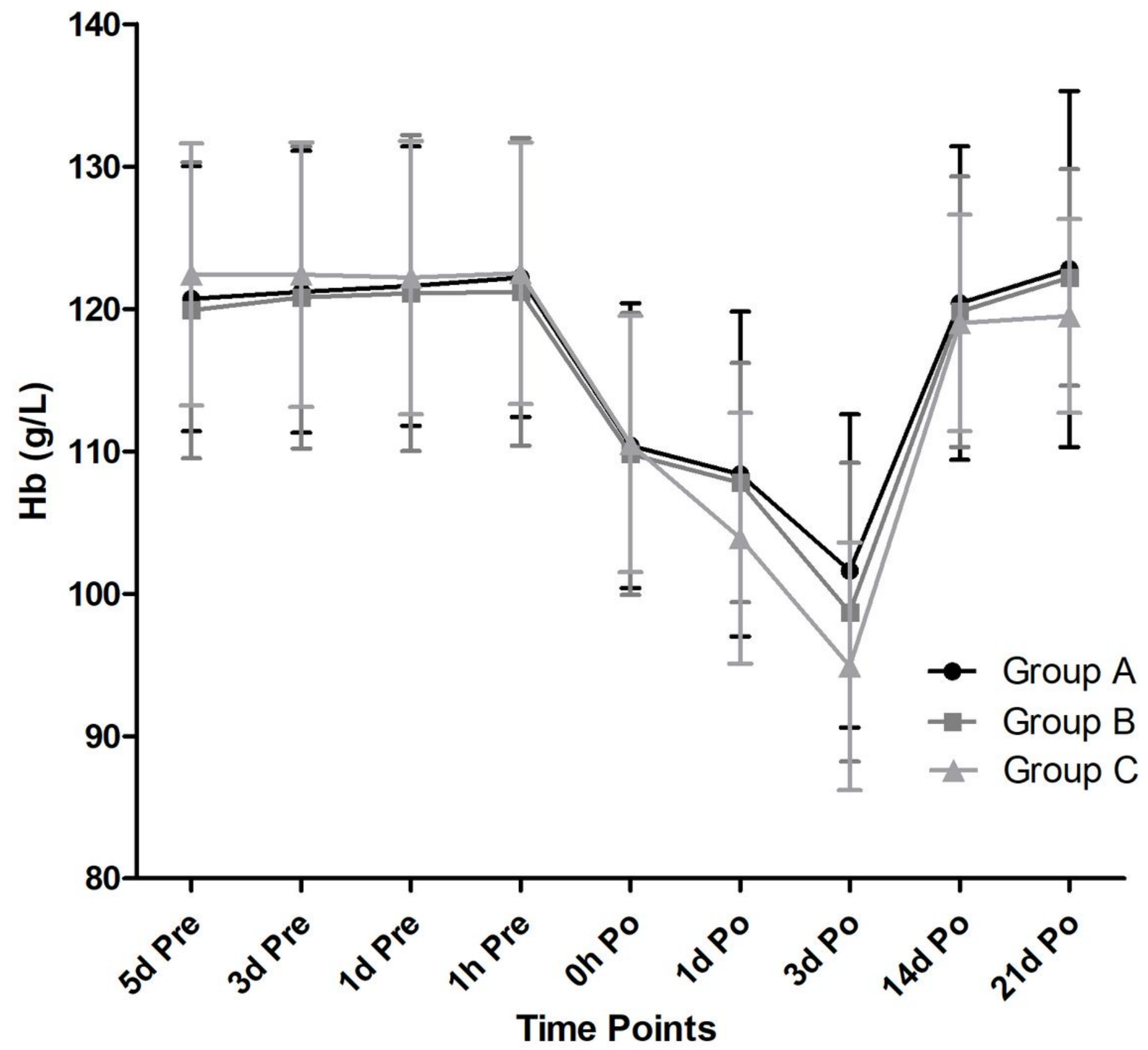

Figure 2

Change in mean $\mathrm{Hb}$ level from baseline during the study 


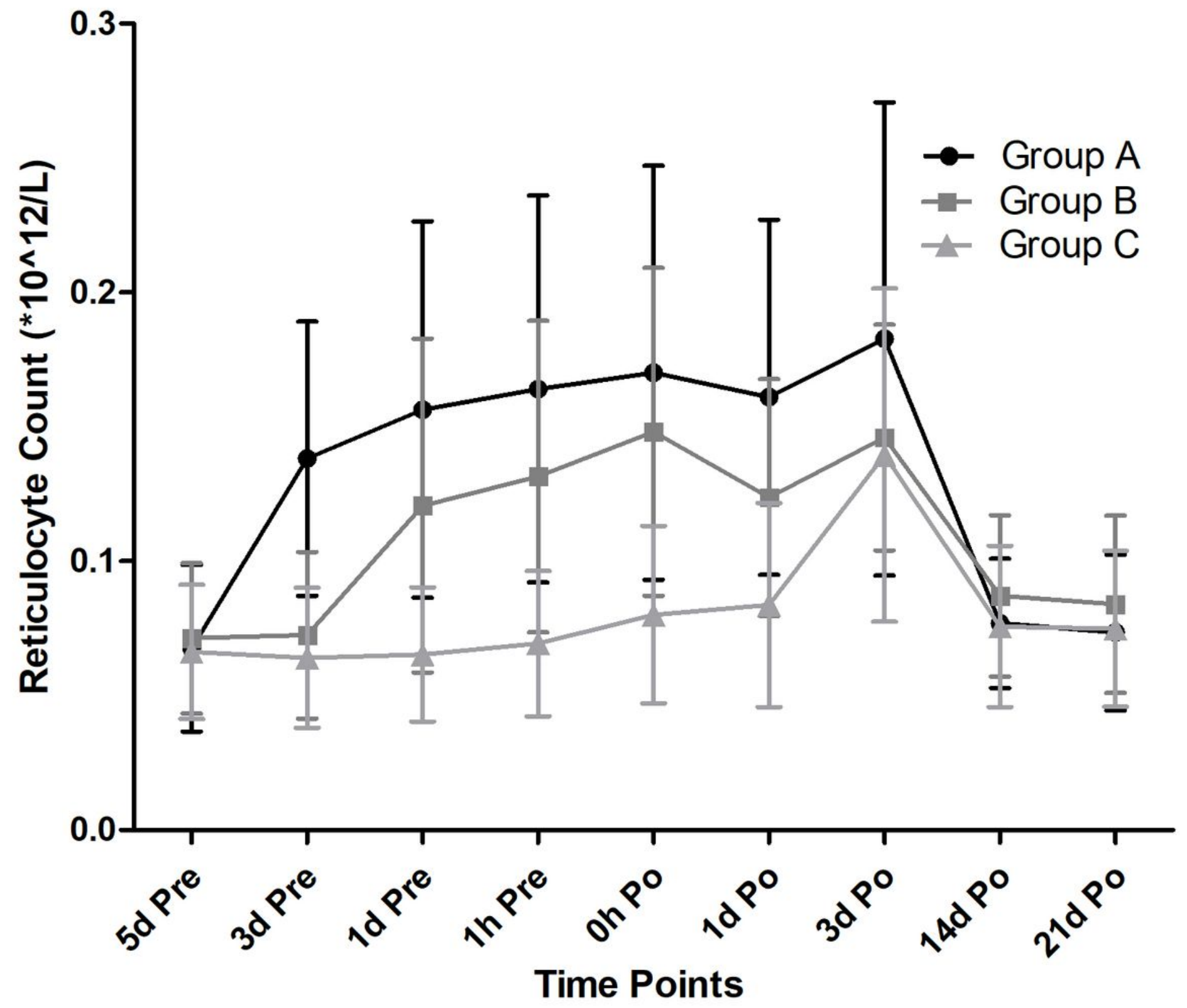

Figure 3

Change in mean reticulocyte count from baseline during the study 